\title{
How SROI provides unique guidance and benefit in society
}

Social Return of Investment (SROI) is an instrumental good to create social resiliency and sustainability, SROI is designed to help to understand and manage society's perception (Vluggen \& Kuijpers \& Jemeijn and Gelderman, 2020). SROI is a pinnacle bridge between the societies and enterprise, there are many beliefs and contradiction between the things People do and what society needs. SROI can only be legitimate if it brings benefit to the person itself. That is why SROI provides a unique mechanism about how to incorporate social values and morality into economic system, but still gain monetary benefit from it (Bellucci \& Nitti \& Franchi \& Testi and Bagnoli, 2019).

SROI provides people with one common goal to pursue, based on the study from (Pratono \& Marciano \& Suyanto and ZurbÜgg, 2017), it has been shown that participants within SROI companies stimulates a strong relationship and affinity with one another, especially within urban areas where it is very hard to find jobs and equal chances, SROI provides a communal sense between members to stray away from things such as drugs and alcohol. Another thing that SROI provides is an education towards society through recycling method from experts. This leads to first communities being aware of waste disposal, second is direct competition for green and clean environmental based. The importance of awareness and real implications of recycling skill is to reduce the amount of waste disposal within urban areas. Waste collectors have also played a role in this where they are able to differentiate organic and non-organic trash, waste collectors can also gain some money in handing these organic and non-organic trash to local businesses that are environmentally friendly. This has also changed how people behave for environment, the SROI program makes not only people being aware of the environmental condition that needs to be preserved, but also makes people care about it and should take care of it. SROI program created a much cleaner and safer environment for families to interact, in 2015 there are many filled issues for divorce and complaints because their spouses are too busy working and their children are too busy playing games, this happens because there is not a shared common activity that families can share. With this program, families start to open their garden and do shared activity. This enhanced the relationship that families have

SROI can provide and incorporate some social values within economic benefit. However there are also many impacts that comes from it. Many communities gain benefit such as behavior changes that are long-term, enjoying clean neighborhood, and able to get some sorts of income. Most of the income comes from people buying their organic compost to be used for gardens and non-consumption based plants, rather than selling it to urban farms that badly needs fertilizer.

In conclusion, the SROI creates social exchanges between people to be able to connect with each other, it has also gave people a chance to get incomes through selling organic and nonorganic trash. There are many benefits that come from SROI program that affects the society in behaviorally, financially, environmentally. 


\section{Bibliography}

Bellucci \& Nitti \& Franchi \& Testi and Bagnoli. (2019). Accounting for social return on investment (SROI): The costs and benefits of family-centred care by the Ronald McDonald House Charities. Social Enterprise Journal, Vol. 15 No. 1, 46-75.

Pratono \& Marciano \& Suyanto and ZurbÜgg. (2017). SOCIAL RETURN ON INVESTMENT FOR COMMUNITY-BASED ENTERPRISE IN SURABAYA CITY. The Hong Kong Journal of Social Work, Vol. 51, No 1/2, 93-114.

Vluggen \& Kuijpers \& Jemeijn and Gelderman. (2020). SROI for green and clean program in Surabaya City. Journal of Public Procurement, Vol. 20 No. 3, 235-264. 